\title{
Osteogenesis and neurogenesis: a robust link also for language evolution
}

\author{
Cedric Boeckx ${ }^{1,2}$ and Antonio Benitez-Burraco ${ }^{3 *}$ \\ ${ }^{1}$ Catalan Institute for Advanced Studies and Research, Barcelona, Spain, ${ }^{2}$ Linguistics, Universitat de Barcelona, Barcelona, \\ Spain, ${ }^{3}$ Spanish Philology and its Didactics, University of Huelva, Huelva, Spain
}

Keywords: osteogenesis, neurogenesis, modern cognition, language evolution, RUNX2

\section{OPEN ACCESS}

Edited by:

Wanda Lattanzi,

Università Cattolica del Sacro Cuore,

Italy

Reviewed by:

Maria Concetta Geloso, Università Cattolica del Sacro Cuore,

Italy

Roberta Perri,

Fondazione IRCCS Santa Lucia, Italy

*Correspondence: Antonio Benítez-Burraco, antonio.benitez@dfesp.uhu.es

Received: 18 March 2015 Accepted: 15 July 2015

Published: 28 July 2015

Citation:

Boeckx C and Benítez-Burraco A

(2015) Osteogenesis and

neurogenesis: a robust link also for language evolution

Front. Cell. Neurosci. 9:291. doi: 10.3389/fncel.2015.00291
This paper seeks to contribute to the characterization of the relation between osteogenesis and neurogenesis by approaching it from the field of the neurobiology of language and cognition; specifically, from an evolutionary perspective. It is difficult to ascertain how the hominin brain changed to support modern language and cognitive abilities because we can only rely on skull remains. But insights can be gained from fossils because the brain and the skull exhibit a tight relationship. Skull shape and brain shape and connectivity influence one another (Roberts et al., 2010; Lieberman, 2011). Craniofacial anomalies and cognitive disorders frequently co-occur (see Boeckx and Benítez-Burraco, 2014a for review). So, "osteo" considerations can shed light on "neuro" considerations (and vice versa). Importantly, main differences between anatomicallymodern humans (AMHs) and Neanderthals pertain not to the brain size, but to the more globularized headshape of the former (Bruner, 2004). Globularity results from an AMH-specific developmental trajectory after birth, at a stage when the brain is the primary determinant of skull shape (Gunz et al., 2010). Globularization is not just a morphological change of the skull. On the contrary, factors giving rise to globularity also have important neurofunctional consequences. The hypothesis we have explored in our recent work is that the rewiring of the hominin brain associated to globularization brought about our most distinctive mode of cognition (see Boeckx and Benítez-Burraco, 2014a for details).

In a series of related papers (Boeckx and Benítez-Burraco, 2014a,b; Benítez-Burraco and Boeckx, 2015) we have examined closely some of the most critical genes that may contribute to skull globularity and that have been selected in AMHs. These also contribute significantly to neurogenesis, as well as to neural specification, arealization of the neo-cortex, neuronal interconnection, and synaptic plasticity. Eventually, the very osteogenic signals that help build our distinctive skull also contributes to build our distinctive mode of brain organization underlying our mode of cognition and language abilities.

Our main candidate is RUNX2. A selective sweep in this gene occurred after our split from Neanderthals (Green et al., 2010). It is a candidate for cleidocranial dysplasia (Yoshida et al., 2003) and controls the closure of cranial sutures (Stein et al., 2004). Together with DLX5 and TLE1 it regulates the integration of the parietal bone (Depew et al., 1999; Stephens, 2006), a "hotspot" for globularization (Bruner, 2004). However, it is also involved in the development of the hippocampal GABAergic neurons as part of the GAD67 regulatory network (Pleasure et al., 2000; Benes et al., 2007). Moreover, it seems to be also involved in the development of thalamus (Reale et al., 2013). Its mutations cause mental diseases in which our mode of cognition is impaired (Talkowski et al., 2012; Ruzicka et al., 2015). Importantly, RUNX2 is deeply implicated in the regulation of osteocalcin (Paredes et al., 2004) and osteopontin (Shen and Christakos, 2005), which are important for both bone formation and brain organization (e.g., osteopontin-deficient mice suffer from thalamic neurodegeneration; Schroeter et al., 2006). 
Interestingly, RUNX2 is functionally connected to many genes that are important for brain and language development, but also to bone formation. To begin with, RUNX2 is a regulatory target of AUTS2 (Oksenberg et al., 2014). AUTS2 is among the genes found to be differentially expressed after RUNX2 transfection in neuroblastomic cell lines (Kuhlwilm et al., 2013). The first half of AUTS2 displays the strongest signal of positive selection in AMHs compared to Neanderthals (Green et al., 2010). Mutations in AUTS2 give rise to a host of cognitive impairments (see Oksenberg and Ahituv, 2013 for review). Interestingly, these routinely co-occur with skeletal abnormalities and/or dysmorphic features (Beunders et al., 2013). AUTS2 interacts with some other proteins like TBR1, RELN, SATB2, GTF2I, ZMAT3, or PRC1 that play a key role at the brain level and have been related to ASD and other developmental disorders affecting cognition and language (Oksenberg and Ahituv, 2013). Some of them directly interact with RUNX2.

For example, RUNX2 directly interacts with SATB2 (Hassan et al., 2010), a gene that regulates stereotypic projections in the cortex (Srinivasan et al., 2012). This gene has been related to ASD, intellectual disability, and language delays, as well as craniofacial defects (Liedén et al., 2014) and plays a key role in osteoblast differentiation, palate formation, and craniofacial development (Zhao et al., 2014). Crucially, the interaction between SATB2 and RUNX2 is very relevant during osteogenesis (Hassan et al., 2010; Gong et al., 2014). Specifically, several micro-RNAs (including miR-205 and miR-31), SATB2, RUNX2, osteopontin and osteocalcin interact complexly to modulate the differentiation of bone mesenchymal stem cells into osteoblasts (Deng et al., 2013; Hu et al., 2015). Interestingly, in the neural satb2 expression depends on both Bmp and Shh (SheehanRooney et al., 2013), which are genes we have highlighted in our previous work. Moreover, SATB2 represses the expression of HOXA2 (Ye et al., 2011), which is one of the targets of the famous "language gene" FOXP2 (Konopka et al., 2009). HOX2A is involved in both the brain and bone formation. Accordingly, it contributes to the hindbrain patterning (Miguez et al., 2012), acting upstream the guidance signals Robo1, Robo2, Slit1, and Slit2 in the anteroposterior migration of pontine neurons (Geisen et al., 2008). However, it also encodes an inhibitor of bone formation (Dobreva et al., 2006; Ye et al., 2011), which controls the morphology of the skeleton (Tavella and Bobola, 2010). Interestingly also, the activation of Hoxa2 in the neural crest downregulates Bmp antagonists and leads to severe craniofacial and brain defects (Garcez et al., 2014).

Additionally, RUNX2 interacts (via FOXO1) with DYRK1A (Huang and Tindall, 2007), a gene located within the Down Syndrome Critical Region on chromosome 21. This gene has been linked to microcephaly, facial dysmorphism, mental retardation, and absence of speech (van Bon et al., 2011; Courcet et al., 2012). DYRK1A has been shown to be involved in bone homeostasis as an inhibitor of osteoclastogenesis (Lee et al., 2009). DYRK1A is also of interest because it phosphorylates SIRT1, which controls neural precursor activity and differentiation (Saharan et al., 2013). SIRT1 both upregulates RUNX2 and deacetylates RUNX2, ultimately promoting osteoblast differentiation (Shakibaei et al., 2012;
Srivastava et al., 2012), an effect which is also due to its effects on $\beta$-catenin and FoxO in osteoblast progenitors (Iyer et al., 2014). Importantly, resveratrol-induced SIRT1 activation promotes neuronal differentiation of human bone marrow mesenchymal stem cells (Joe et al., 2015). Finally, RUNX2 is also functionally related (via AUTS2) to $C B L$, in turn linked to Noonan syndrome-like disorder, a condition involving facial dysmorphism, a reduced growth, and several cognitive deficits (Martinelli et al., 2010). This gene, which encodes an inhibitor of osteoblast differentiation and promotes the degradation of Osterix (Choi et al., 2015), is located within a region showing signals of a strong selective sweep in AMHs compared to Altai Neanderthals (Prüfer et al., 2014).

RUNX2 is also functionally directly linked to the FOXP2 and ROBO1 interactomes (see Boeckx and Benítez-Burraco, 2014b for details), which are related to language disorders and vocal learning (Graham and Fisher, 2013; Pfenning et al., 2014). To begin with, a direct interaction between RUNX2 and FOXP2 has recently been experimentally demonstrated (Zhao et al., 2015b). This finding was further reinforced in Gascoyne et al. (2015), who added FOXP2 to the list of established osteoblast and chondrocyte transcription factors such RUNX2, SP7, and SOX9. In fact, FOXP2 seems to regulate both bone formation (it regulates endochondral ossification) (Zhao et al., 2015b), and the fate of neural stem cells during corticogenesis (MuhChyi et al., 2013). As for the ROBO suite, some members like HES1 and AKT1 are functionally related to RUNX2. HES1 is needed for the correct functioning of the Slit/Robo signaling pathway during neurogenesis (Borrell et al., 2012) and plays a role as well in the development of both GABAergic and dopaminergic neurons. Hes 1 silencing promotes bone marrow mesenchymal stem cells to differentiate into GABAergic neuron-like cells in vitro (Long et al., 2013). Moreover, Hes1 modulates skeletal formation and pathogenesis of osteoarthritis via calcium/calmodulin interaction (Sugita et al., 2015). In turn AKT1 is a critical mediator of growth factor-induced neuronal survival (Dudek et al., 1997). In mice mutations in Akt1 and Akt2 impair bone formation (Peng et al., 2003). AKT1 has recently been shown to coordinate the boneforming osteoblasts and bone-resorbing osteoclasts, a process important for maintaining skeletal integrity (Akt1 deficiency impairs osteoclast differentiation and diminishes the rate of proliferation of osteoblast progenitors) (Mukherjee et al., 2014).

Other bone morphogenetic factors may well play a key role in the emergence of our language-readiness and our globular brain. Among them we wish highlight the DLX suite (particularly, $D L X 1, D L X 2, D L X 5$, and $D L X 6)$ and the BMP suite (specifically, $B M P 2$ and BMP7): most of them also interact with RUNX2. Consider, e.g., DLX2. It is involved in craniofacial development (Jeong et al., 2008), but it is also needed for neocortical and thalamic growth (Jones and Rubenstein, 2004). Mutations in this gene affect craniofacial and bone development (Kraus and Lufkin, 2006), but also cognitive development (Liu et al., 2009). It also takes part in the regulation of neuronal proliferation within the cortex (McKinsey et al., 2013). Concerning the BMP proteins, both BMP2 and BMP7 interact with RUNX2 and both of them play a role in bone and brain formation. $B M P 2$ promotes the differentiation of mesenchymal cells into bone cells (Dwivedi 
et al., 2012), but it is also needed for normal neurogenesis in the ganglionic eminences and correct cortical neurogenesis (Shakèd et al., 2008). In mice Bmp2 (and also Bmp7) upregulates Dlx1, Dlx2, Dlx5, and Runx2 (Bustos-Valenzuela et al., 2011). Much like $B M P 2, B M P 7$ is involved in osteogenesis (Cheng et al., 2003) and skull and brain development (Segklia et al., 2012). Mutations in this gene give rise as well to developmental delay and learning disabilities (Wyatt et al., 2010).

We further believe that the genetic aspects highlighted here may contribute not only to gain a better understanding of the way in which both aspects of our modernity emerged and interact, but specifically to tune the crosstalk between the osteogenic and neurogenic stem cell niches. Zhao et al. (2015a) have recently identified Gli1+ cells within the suture mesenchyme as the main mesenchymal stem cell population for craniofacial bones. Ablation of these Gli1+ cells leads to craniosynostosis, known to be associated with cognitive deficits (Starr et al., 2007), and arrest of skull growth. Not surprisingly, Gli1 is known to regulate Runx2 (Kim et al., 2013). In turn, Gli1 transcriptional activity is regulated by Dyrk1a (Mao et al., 2002), whereas Hes1 directly modulates Gli1 expression (Schreck et al., 2010). Moreover, Gli1 is the direct response gene of Shh (Liu et al., 1998). The Shh-Gli1 pathway has been shown to regulate brain growth (Dahmane et al., 2001; Ruiz i Altaba et al., 2002; Corrales et al., 2004), and to control thalamic progenitor identity and nuclei specification (Vue et al., 2009), as well as the development of the cerebellum (Lee et al., 2010). It may also be the case that FoxP2 lies downstream of Shh, as suggested by Scharff and Haesler (2005), who observed that the zinc finger motif of FoxP2 is highly homologous to those of the major Shh downstream transcriptional effectors,

\section{References}

Benes, F. M., Lim, B., Matzilevich, D., Walsh, J. P., Subburaju, S., and Minns, M. (2007). Regulation of the GABA cell phenotype in hippocampus of schizophrenics and bipolars. Proc. Natl. Acad. Sci. U.S.A. 104, 10164-10169. doi: 10.1073 /pnas.0703806104

Benítez-Burraco, A., and Boeckx, C. (2015). Possible functional links among brainand skull-related genes selected in modern humans. Front. Psychol. 6:794. doi: 10.3389/fpsyg.2015.00794

Beunders, G., Voorhoeve, E., Golzio, C., Pardo, L. M., Rosenfeld, J. A., Talkowski, M. E., et al. (2013). Exonic deletions in AUTS2 cause a syndromic form of intellectual disability and suggest a critical role for the C Terminus. Am. J. Hum. Genet. 92, 210-220. doi: 10.1016/j.ajhg.2012.12.011

Boeckx, C., and Benítez-Burraco, A. (2014a). The shape of the human languageready brain. Front. Psychol. 5:282. doi: 10.3389/fpsyg.2014.00282

Boeckx, C., and Benítez-Burraco, A. (2014b). Globularity and language-readiness: generating new predictions by expanding the set of genes of interest. Front. Psychol. 5:1324. doi: 10.3389/fpsyg.2014.01324

Borrell, V., Cárdenas, A., Ciceri, G., Galcerán, J., Flames, N., Pla, R., et al. (2012). Slit/Robo signaling modulates the proliferation of central nervous system progenitors. Neuron 76, 338-352. doi: 10.1016/j.neuron.2012.08.003

Bruner, E. (2004). Geometric morphometrics and paleoneurology: brain shape evolution in the genus homo. J. Hum. Evol. 47, 279-303. doi: 10.1016/j.jhevol.2004.03.009

Bustos-Valenzuela, J. C., Fujita, A., Halcsik, E., Granjeiro, J. M., and Sogayar, M. C. (2011). Unveiling novel genes upregulated by both rhBMP2 and rhBMP7 during early osteoblastic transdifferentiation of $\mathrm{C} 2 \mathrm{C} 12$ cells. BMC Res. 4:370. doi: 10.1186/1756-0500-4-370 particularly, of Gli1, Gli2, and Gli3. Moreover, balanced Shh signaling is required for proper formation and maintenance of dorsal telencephalic midline structure (Himmelstein et al., 2010). Dysregulation of the neural stem cell pathway ShhGli1 has been observed in autoimmune encephalomyelitis and multiple sclerosis (Wang et al., 2008). As a matter of fact, a GLI1-p53 inhibitory loop controls neural stem cell (Stecca and Ruiz i Altaba, 2009). Most interestingly for us, Marcucio et al. (2005) have shown that excessive Shh activity, caused by truncating the primary cilia on cranial neural crest cells, causes hypertelorism, and frontonasal dysplasia. This condition has been shown to be associated to mental retardation, lack of language acquisition, and severe central nervous system deficiencies (Guion-Almeida and Richieri-Costa, 2009). The latter example appears to lend credence to our final claim that language and cognition are intimately related to the molecular mechanisms associated with mesenchymal stem cell and neural stem cell populations.

\section{Acknowledgments}

Preparation of this work was supported by funds from the Spanish Ministry of Economy and Competitiveness (grants FFI2013-43823-P and FFI2014-61888-EXP), as well as funds from a Marie Curie International Reintegration Grant from the European Union (PIRG-GA-2009-256413), research funds from the Fundació Bosch i Gimpera, and from the Generalitat de Catalunya (2014-SGR-200). In addition to the reviewers, we wish to thank Bridget Samuels for bringing the relevance of GLI1 to our attention, and Constantina Theofanopoulou for illuminating discussions at all stages of our research.
Cheng, H., Jiang, W., Phillips, F. M., Haydon, R. C., Peng, Y., Zhou, L., et al. (2003). Osteogenic activity of the fourteen types of human bone morphogenetic proteins (BMPs). J. Bone Joint. Surg. Am. 85, 1544-1552.

Choi, Y. H., Han, Y., Lee, S. H., Jin, Y. H., Bahn, M., Hur, K. C., et al. (2015). Cbl-b and c-Cbl negatively regulate osteoblast differentiation by enhancing ubiquitination and degradation of Osterix. Bone 75, 201-209. doi: 10.1016/j.bone.2015.02.026

Corrales, J. D., Rocco, G. L., Blaess, S., Guo, Q., and Joyner, A. L. (2004). Spatial pattern of sonic hedgehog signaling through Gli genes during cerebellum development. Development 131, 5581-5590. doi: 10.1242/dev.01438

Courcet, J. B., Faivre, L., Malzac, P., Masurel-Paulet, A., López, E., Callier, P., et al. (2012). The DYRK1A gene is a cause of syndromic intellectual disability with severe microcephaly and epilepsy. J. Med. Genet. 49, 731-736. doi: 10.1136/jmedgenet-2012-101251

Dahmane, N., Sánchez, P., Gitton, Y., Palma, V., Sun, T., Beyna, M., et al. (2001). The Sonic Hedgehog-Gli pathway regulates dorsal brain growth and tumorigenesis. Development 128, 5201-5212.

Deng, Y., Wu, S., Zhou, H., Bi, X., Wang, Y., Hu, Y., et al. (2013). Effects of a miR-31, Runx2, and Satb2 regulatory loop on the osteogenic differentiation of bone mesenchymal stem cells. Stem Cells Dev. 22, 2278-2286. doi: 10.1089/scd.2012.0686

Depew, M. J., Liu, J. K., Long, J. E., Presley, R., Meneses, J. J., Pedersen, R. A., et al. (1999). Dlx5 regulates regional development of the branchial arches and sensory capsules. Development 126, 3831-3846.

Dobreva, G., Chahrour, M., Dautzenberg, M., Chirivella, L., Kanzler, B., Fariñas, I., et al. (2006). SATB2 is a multifunctional determinant of craniofacial patterning and osteoblast differentiation. Cell 125, 971-986. doi: 10.1016/j.cell.2006. 05.012 
Dudek, H., Datta, S. R., Franke, T. F., Birnbaum, M. J., Yao, R., Cooper, G. M., et al. (1997). Regulation of neuronal survival by the serine-threonine protein kinase Akt. Science 275, 661-665. doi: 10.1126/science.275.5300.661

Dwivedi, P. P., Anderson, P. J., and Powell, B. C. (2012). Development of an efficient, non-viral transfection method for studying gene function and bone growth in human primary cranial suture mesenchymal cells reveals that the cells respond to BMP2 and BMP3. BMC Biotechnol. 12:45. doi: 10.1186/14726750-12-45

Garcez, R. C., Le Douarin, N. M., and Creuzet, S. E. (2014). Combinatorial activity of Six1-2-4 genes in cephalic neural crest cells controls craniofacial and brain development. Cell Mol. Life Sci. 71, 2149-2164. doi: 10.1007/s00018-013-1477-z

Gascoyne, D. M., Spearman, H., Lyne, L., Puliyadi, R., Pérez-Alcántara, M., Coulton, L., et al. (2015). The forkhead transcription factor FOXP2 is required for regulation of p21WAF1/CIP1 in 143B osteosarcoma cell growth arrest. PLoS ONE 10:e0128513. doi: 10.1371/journal.pone.0128513

Geisen, M. J., Di Meglio, T., Pasqualetti, M., Ducret, S., Brunet, J. F., Chedotal, A., et al. (2008). Hox paralog group 2 genes control the migration of mouse pontine neurons through slit-robo signaling. PLoS Biol. 6:e142. doi: 10.1371/journal.pbio.0060142

Gong, Y., Qian, Y., Yang, F., Wang, H., and Yu, Y. (2014). Lentiviral-mediated expression of SATB2 promotes osteogenic differentiation of bone marrow stromal cells in vitro and in vivo. Eur. J. Oral Sci. 122, 190-197. doi: $10.1111 /$ eos. 12122

Graham, S. A., and Fisher, S. E. (2013). Decoding the genetics of speech and language. Curr. Opin. Neurobiol. 23, 43-51. doi: 10.1016/j.conb.2012.11.006

Green, R. E., Krause, J., Briggs, A. W., Maricic, T., Stenzel, U., Kircher, M., et al. (2010). A draft sequence of the Neandertal genome. Science 328, 710-722. doi: $10.1126 /$ science. 1188021

Guion-Almeida, M. L., and Richieri-Costa, A. (2009). Frontonasal dysplasia, severe neuropsychological delay, and midline central nervous system anomalies: report of 10 Brazilian male patients. Am. J. Med. Genet. A 149A, 1006-1011. doi: 10.1002/ajmg.a.32717

Gunz, P., Neubauer, S., Maureille, B., and Hublin, J.-J. (2010). Brain development after birth differs between Neanderthals and modern humans. Curr. Biol. 20, R921-R922. doi: 10.1016/j.cub.2010.10.018

Hassan, M. Q., Gordon, J. A., Beloti, M. M., Croce, C. M., van Wijnen, A. J., Stein, J. L., et al. (2010). A network connecting Runx2, SATB2, and the miR-23a $\sim 27 a \sim 24-2$ cluster regulates the osteoblast differentiation program. Proc. Natl. Acad. Sci. U.S.A. 107, 19879-19884. doi: 10.1073/pnas.10076 98107

Himmelstein, D. S., Bi, C., Clark, B. S., Bai, B., and Kohtz, J. D. (2010). Balanced Shh signaling is required for proper formation and maintenance of dorsal telencephalic midline structures. BMC Dev. Biol. 10:118. doi: 10.1186/1471213X-10-118

Hu, N., Feng, C., Jiang, Y., Miao, Q., and Liu, H. (2015). Regulative effect of mir205 on osteogenic differentiation of bone mesenchymal stem cells (BMSCs): possible role of SATB2/Runx2 and ERK/MAPK pathway. Int. J. Mol. Sci. 16, 10491-10506. doi: 10.3390/ijms160510491

Huang, H., and Tindall, D. J. (2007). Dynamic FoxO transcription factors. J. Cell Sci. 120, 2479-2487. doi: $10.1242 /$ jcs.001222

Iyer, S., Han, L., Bartell, S. M., Kim, H. N., Gubrij, I., de Cabo, R., et al. (2014). Sirtuin1 (Sirt1) promotes cortical bone formation by preventing $\beta$-catenin sequestration by FoxO transcription factors in osteoblast progenitors. J. Biol. Chem. 289, 24069-24078. doi: 10.1074/jbc.M114.561803

Jeong, J., Li, X., McEvilly, R. J., Rosenfeld, M. G., Lufkin, T., and Rubenstein, J. L. (2008). Dlx genes pattern mammalian jaw primordium by regulating both lower jaw-specific and upper jaw-specific genetic programs. Development 135, 2905-2916. doi: 10.1242/dev.019778

Joe, I. S., Jeong, S. G., and Cho, G. W. (2015). Resveratrol-induced SIRT1 activation promotes neuronal differentiation of human bone marrow mesenchymal stem cells. Neurosci. Lett. 584, 97-102. doi: 10.1016/j.neulet.2014.10.024

Jones, E. G., and Rubenstein, J. L. (2004). Expression of regulatory genes during differentiation of thalamic nuclei in mouse and monkey. J. Comp. Neurol. 477, 55-80. doi: 10.1002/cne.20234

Kim, E. J., Cho, S. W., Shin, J. O., Lee, M. J., Kim, K. S., and Jung, H. S. (2013). Ihh and Runx2/Runx3 signaling interact to coordinate early chondrogenesis: a mouse model. PLoS ONE 8:e55296. doi: 10.1371/journal.pone.00 55296
Konopka, G., Bomar, J. M., Winden, K., Coppola, G., Jonsson, Z. O., Gao, F., et al. (2009). Human-specific transcriptional regulation of CNS development genes by FOXP2. Nature 462, 213-217. doi: 10.1038/nature08549

Kraus, P., and Lufkin, T. (2006). Dlx homeobox gene control of mammalian limb and craniofacial development. Am. J. Med. Genet. A. 140, 1366-1374. doi: 10.1002/ajmg.a.31252

Kuhlwilm, M., Davierwala, A., and Pääbo, S. (2013). Identification of putative target genes of the transcription factor RUNX2. PLoS ONE 8:e83218. doi: 10.1371/journal.pone.0083218

Lee, E. Y., Ji, H., Ouyang, Z., Zhou, B., Ma, W., Vokes, S. A., et al. (2010). Hedgehog pathway-regulated gene networks in cerebellum development and tumorigenesis. Proc. Natl. Acad. Sci. U.S.A. 107, 9736-9741. doi: 10.1073/pnas. 1004602107

Lee, Y., Ha, J., Kim, H. J., Kim, Y. S., Chang, E. J., Song, W. J., et al. (2009). Negative feedback Inhibition of NFATc1 by DYRK1A regulates bone homeostasis. J. Biol. Chem. 284, 33343-33351. doi: 10.1074/jbc.M109.042234

Lieberman, D. E. (2011). The Evolution of the Human Head. Cambridge, MA: Harvard University Press.

Liedén, A., Kvarnung, M., Nilssson, D., Sahlin, E., and Lundberg, E. S. (2014). Intragenic duplication-A novel causative mechanism for SATB2-associated syndrome. Am. J. Med. Genet. A. 164A, 3083-3087. doi: 10.1002/ajmg.a.36769

Liu, C. Z., Yang, J. T., Yoon, J. W., Villavicencio, E., Pfendler, K., Walterhouse, D., et al. (1998). Characterization of the promoter region and genomic organization of GLI, a member of the Sonic hedgehog-Patched signaling pathway. Gene 209, 1-11. doi: 10.1016/S0378-1119(97)00668-9

Liu, X., Novosedlik, N., Wang, A., Hudson, M. L., Cohen, I. L., Chudley, A. E., et al. (2009). The DLX1and DLX2 genes and susceptibility to autism spectrum disorders. Eur. J. Hum. Genet. 17, 228-235. doi: 10.1038/ejhg.2008.148

Long, Q., Qiu, B., Wang, K., Yang, J., Jia, C., Xin, W., et al. (2013). Genetically engineered bone marrow mesenchymal stem cells improve functional outcome in a rat model of epilepsy. Brain. Res. 1532, 1-13. doi: 10.1016/j.brainres.2013.07.020

Mao, J., Maye, P., Kogerman, P., Tejedor, F. J., Toftgard, R., Xie, W., et al. (2002). Regulation of Gli1 transcriptional activity in the nucleus by Dyrk1. J. Biol. Chem. 277, 35156-35161. doi: 10.1074/jbc.M206743200

Marcucio, R. S., Cordero, D. R., Hu, D. and Helms, J. A. (2005). Molecular interactions coordinating the development of the forebrain and face. Dev. Biol. 284, 48-61. doi: 10.1016/j.ydbio.2005.04.030

Martinelli, S., De Luca, A., Stellacci, E., Rossi, C., Checquolo, S., Lepri, F., et al. (2010). Heterozygous germline mutations in the CBL tumor-suppressor gene cause a Noonan syndrome-like phenotype. Am. J. Hum. Genet. 87, 250-257 doi: 10.1016/j.ajhg.2010.06.015

McKinsey, G. L., Lindtner, S., Trzcinski, B., Visel, A., Pennacchio, L. A., Huylebroeck, D., et al. (2013). Dlx1\&2-dependent expression of Zfhx1b (Sip1, Zeb2) regulates the fate switch between cortical and striatal interneurons. Neuron 77, 83-98. doi: 10.1016/j.neuron.2012.11.035

Miguez, A., Ducret, S., Di Meglio, T., Parras, C., Hmidan, H., Haton, C., et al. (2012). Opposing roles for Hoxa2 and Hoxb2 in hindbrain oligodendrocyte patterning. J. Neurosci. 32, 17172-17185. doi: 10.1523/JNEUROSCI.088512.2012

MuhChyi, C., Juliandi, B., Matsuda, T., and Nakashima, K. (2013). Epigenetic regulation of neural stem cell fate during corticogenesis. Int. J. Dev. Neurosci. 31, 424-433. doi: 10.1016/j.ijdevneu.2013.02.006

Mukherjee, A., Larson, E. A., Klein, R. F., and Rotwein, P. (2014). Distinct actions of akt1 on skeletal architecture and function. PLoS ONE 9:e93040. doi: 10.1371/journal.pone.0093040

Oksenberg, N., and Ahituv, N. (2013). The role of AUTS2 in neurodevelopment and human evolution. Trends Genet. 29, 600-608. doi: 10.1016/j.tig.2013. 08.001

Oksenberg, N., Haliburton, G. D., Eckalbar, W. L., Oren, I., Nishizaki, S., Murphy, K., et al. (2014). Genome-wide distribution of Auts2 binding localizes with active neurodevelopmental genes. Transl. Psychiatry 4, e431. doi: $10.1038 /$ tp. 2014.78

Paredes, R., Arriagada, G., Cruzat, F., Villagra, A., Olate, J., Zaidi, K., et al. (2004). Bone-specific transcription factor Runx2 interacts with the $1 \alpha, 25-$ dihydroxyvitamin $\mathrm{D}_{3}$ receptor to up-regulate rat osteocalcin gene expression in osteoblastic cells. Mol. Cell Biol. 24, 8847-8861. doi: 10.1128/MCB.24.20.88478861.2004 
Peng, X. D., Xu, P. Z., Chen, M. L., Hahn-Windgassen, A., Skeen, J., and Jacobs, J. (2003). Dwarfism, impaired skin development, skeletal muscle atrophy, delayed bone development, and impeded adipogenesis in mice lacking Akt1 and Akt2. Genes Dev. 17, 1352-1365. doi: 10.1101/gad.1089403

Pfenning, A. R., Hara, E., Whitney, O., Rivas, M. V., Wang, R., Roulhac, P. L., et al. (2014). Convergent transcriptional specializations in the brains of humans and songlearning birds. Science 346:1256846. doi: 10.1126/science.1256846

Pleasure, S. J., Anderson, S., Hevner, R., Bagri, A., Marin, O., Lowenstein, D. H., et al. (2000). Cell migration from the ganglionic eminences is required for the development of hippocampal GABAergic interneurons. Neuron 28, 727-740. doi: 10.1016/S0896-6273(00)00149-5

Prüfer, K., Racimo, F., Patterson, N., Jay, F., Sankararaman, S., Sawyer, S., et al. (2014). The complete genome sequence of a Neanderthal from the Altai Mountains. Nature 505, 43-49. doi: 10.1038/nature12886

Reale, M. E., Webb, I. C., Wang, X., Baltazar, R. M., Coolen, L. M., and Lehman, M. N. (2013). The transcription factor Runx2 is under circadian control in the suprachiasmatic nucleus and functions in the control of rhythmic behavior. PLoS ONE 8:e54317. doi: 10.1371/journal.pone.0054317

Roberts, T., McGreevy, P., and Valenzuela, M. (2010). Human induced rotation and reorganization of the brain of domestic dogs. PLOS ONE 5:e11946. doi: 10.1371/journal.pone.0011946

Ruiz i Altaba, A., Palma, V., and Dahmane, N. (2002). Hedgehog-Gli signalling and the growth of the brain. Nat. Rev. Neurosci. 3, 24-33. doi: 10.1038/nrn704

Ruzicka, W. B., Subburaju, S., and Benes, F. M. (2015). Circuit- and diagnosisspecific DNA methylation changes at $\gamma$-aminobutyric acid-related genes in postmortem human hippocampus in schizophrenia and bipolar disorder. JAMA Psychiatry 72, 541-551. doi: 10.1001/jamapsychiatry.2015.49

Saharan, S., Jhaveri, D. J., and Bartlett, P. F. (2013). SIRT1 regulates the neurogenic potential of neural precursors in the adult subventricular zone and hippocampus. J. Neurosci. Res. 91, 642-659. doi: 10.1002/jnr.23199

Scharff, C., and Haesler, S. (2005). An evolutionary perspective on FoxP2: strictly for the birds? Curr. Opin. Neurobiol. 15, 694-703. doi: 10.1016/j.conb.2005.10.004

Schreck, K. C., Taylor, P., Marchionni, L., Gopalakrishnan, V., Bar, E. E., Gaiano, N., et al. (2010). The Notch target Hesl directly modulates Glil expression and Hedgehog signaling: a potential mechanism of therapeutic resistance. Clin. Cancer Res. 16, 6060-6070. doi: 10.1158/1078-0432.CCR-10-1624

Schroeter, M., Zickler, P., Denhardt, D. T., Hartung, H. P., and Jander, S. (2006). Increased thalamic neurodegeneration following ischaemic cortical stroke in osteopontin-deficient mice. Brain 129, 1426-1437. doi: 10.1093/brain/awl094

Segklia, A., Seuntjens, E., Elkouris, M., Tsalavos, S., Stappers, E., Mitsiadis, T. A., et al. (2012). Bmp7 regulates the survival, proliferation, and neurogenic properties of neural progenitor cells during corticogenesis in the mouse. PLoS ONE 7:e34088. doi: 10.1371/journal.pone.0034088

Shakèd, M., Weissmüller, K., Svoboda, H., Hortschansky, P., Nishino, N., Wölfl, S., et al. (2008). Histone deacetylases control neurogenesis in embryonic brain by inhibition of BMP2/4 signaling. PLOS ONE 3:e2668. doi: 10.1371/journal.pone.0002668

Shakibaei, M., Shayan, P., Busch, F., Aldinger, C., Buhrmann, C., Lueders, C., et al. (2012). Resveratrol mediated modulation of Sirt-1/Runx 2 promotes osteogenic differentiation of mesenchymal stem cells: potential role of Runx2 deacetylation. PLoS ONE 7:e35712. doi: 10.1371/journal.pone.0035712

Sheehan-Rooney, K., Swartz, M. E., Lovely, C. B., Dixon, M. J., and Eberhart, J. K. (2013). Bmp and Shh signaling mediate the expression of satb2 in the pharyngeal arches. PLoS ONE 8:e59533. doi: 10.1371/journal.pone.0059533

Shen, Q., and Christakos, S. (2005). The vitamin D receptor, Runx2, and the Notch signaling pathway cooperate in the transcriptional regulation of osteopontin. J. Biol. Chem. 280, 40589-40598. doi: 10.1074/jbc.M504166200

Srinivasan, K., Leone, D. P., Bateson, R. K., Dobreva, G., Kohwi, Y., KohwiShigematsu, T., et al. (2012). A network of genetic repression and derepression specifies projection fates in the developing neocortex. Proc. Natl. Acad. Sci. U.S.A. 109, 19071-19078. doi: 10.1073/pnas.1216793109

Srivastava, S., Bedi, U., and Roy, P. (2012). Synergistic actions of insulinsensitive and Sirtl-mediated pathways in the differentiation of mouse embryonic stem cells to osteoblast. Mol. Cell Endocrinol. 361, 153-164. doi: 10.1016/j.mce.2012.04.002

Starr, J. R., Kapp-Simon, K. A., Cloonan, Y. K., Collett, B. R., Cradock, M. M., Buono, L., et al. (2007). Presurgical and postsurgical assessment of the neurodevelopment of infants with single-suture craniosynostosis: comparison with controls. J. Neurosurg. 107, 103-110. doi: 10.3171/ped-07/08/103

Stecca, B., and Ruiz i Altaba, A. (2009). A GLI1-p53 inhibitory loop controls neural stem cell and tumour cell numbers. EMBO J. 28, 663-676. doi: 10.1038/emboj.2009.16

Stein, G. S., Lian, J. B., van Wijnen, A. J., Stein, J. L., Montecino, M., Javed, A., et al. (2004). Runx2 control of organization assembly and activity of the regulatory machinery for skeletal gene expression. Oncogene 23, 4315-4329. doi: $10.1038 /$ sj.onc. 1207676

Stephens, A. (2006). Genetic and Functional Characterization of RUNX2. Ph.D. dissertation, Brisbane: Griffith University.

Sugita, S., Hosaka, Y., Okada, K., Mori, D., Yano, F., Kobayashi, H., et al. (2015). Transcription factor Hes1 modulates osteoarthritis development in cooperation with calcium/calmodulin-dependent protein kinase 2 . Proc. Natl. Acad. Sci. U.S.A. 112, 3080-3085. doi: 10.1073/pnas.14196 99112

Talkowski, M. E., Rosenfeld, J. A., Blumenthal, I., Pillalamarri, V., Chiang, C., Heilbut, A., et al. (2012). Sequencing chromosomal abnormalities reveals neurodevelopmental loci that confer risk across diagnostic boundaries. Cell 149, 525-537. doi: 10.1016/j.cell.2012.03.028

Tavella, S., and Bobola, N. (2010). Expressing Hoxa2 across the entire endochondral skeleton alters the shape of the skeletal template in a spatially restricted fashion. Differentiation 79, 194-202. doi: 10.1016/j.diff.2009. 11.004

van Bon, B. W. M., Hoischen, A., Hehir-Kwa, J., de Brouwer, A. P. M., Ruivenkamp, C., Gijsbers, A. C. J., et al. (2011). Intragenic deletion in DYRK1A leads to mental retardation and primary microcephaly. Clin. Genet. 79, 296-299. doi: 10.1111/j.1399-0004.2010.01544.x

Vue, T. Y., Bluske, K., Alishahi, A., Yang, L. L., Koyano-Nakagawa, N., Novitch, B., et al. (2009). Sonic hedgehog signaling controls thalamic progenitor identity and nuclei specification in mice. J. Neurosci. 29, 4484-4497. doi: 10.1523/JNEUROSCI.0656-09.2009

Wang, Y., Imitola, J., Rasmussen, S., O’Connor, K. C., and Khoury, S. J. (2008). Paradoxical dysregulation of the neural stem cell pathway sonic hedgehogGli1 in autoimmune encephalomyelitis and multiple sclerosis. Ann. Neurol. 64, 417-427. doi: 10.1002/ana.21457

Wyatt, A. W., Osborne, R. J., Stewart, H., and Ragge, N. K. (2010). Bone morphogenetic protein 7 (BMP7) mutations are associated with variable ocular, brain, ear, palate, and skeletal anomalies. Hum. Mutat. 31, 781-787. doi: 10.1002/humu.21280

Ye, J. H., Xu, Y. J., Gao, J., Yan, S. G., Zhao, J., Tu, Q., et al. (2011). Critical-size calvarial bone defects healing in a mouse model with silk scaffolds and SATB2-modified iPSCs. Biomaterials 32, 5065-5076. doi: 10.1016/j.biomaterials.2011.03.053

Yoshida, T., Kanegane, H., Osato, M., Yanagida, M., Miyawaki, T., Ito, Y., et al. (2003). Functional analysis of RUNX2 mutations in cleidocranial dysplasia: novel insights into genotype-phenotype correlations. Blood Cells Mol. Dis. 30, 184-193. doi: 10.1016/S1079-9796(03)00020-2

Zhao, H., Feng, J., Ho, T. V., Grimes, W., Urata, M., and Chai, Y. (2015a). The suture provides a niche for mesenchymal stem cells of craniofacial bones. Nat. Cell. Biol. 17, 386-396. doi: 10.1038/ncb3139

Zhao, H., Zhou, W., Yao, Z., Wan, Y., Cao, J., Zhang, L., et al. (2015b). Foxp1/2/4 regulate endochondral ossification as a suppresser complex. Dev. Biol. 398, 242-254. doi: 10.1016/j.ydbio.2014.12.007

Zhao, X., Qu, Z., Tickner, J., Xu, J., Dai, K., and Zhang, X. (2014). The role of SATB2 in skeletogenesis and human disease. Cytokine Growth Factor Rev. 25, 35-44. doi: 10.1016/j.cytogfr.2013.12.010

Conflict of Interest Statement: The authors declare that the research was conducted in the absence of any commercial or financial relationships that could be construed as a potential conflict of interest.

Copyright (c) 2015 Boeckx and Benitez-Burraco. This is an open-access article distributed under the terms of the Creative Commons Attribution License (CC BY). The use, distribution or reproduction in other forums is permitted, provided the original author(s) or licensor are credited and that the original publication in this journal is cited, in accordance with accepted academic practice. No use, distribution or reproduction is permitted which does not comply with these terms. 